\title{
A Rediscovery of Voice: The Story of Self Through a Qualitative Lens
}

\author{
Sabina Choudhury
}

\begin{abstract}
The following article tells the story of how a qualitative research methods $\mathrm{PhD}$ course and the creation of a researcher portfolio helped to answer the sometimes elusive question of, "Who am I as a researcher?" and ultimately led to a rediscovery of voice. This story describes how using various modes of inquiry set the groundwork for my rediscovery of voice. This is my story. This is my story about voice. This is my story about how this PhD course provided the starting point to discover who I was as a researcher, and, more importantly, allowed me to reclaim my lost voice.
\end{abstract}

\section{Background}

The strength of story-telling lies in its ability to transmit and teach information to others, acting as a means to learn and unleash the power of voice. My reference to voice lies not only in the verbal expression of words, but also in the overall expression and description of thoughts, of emotions, of heart, in whatever form. In her book The Lowland, Lahiri (2014) writes, "His hands seemed an extension of his voice, always in motion, embellishing the things he said" (p. 62). For me, this is a beautiful depiction of voice and reminds me of the power of stories to convey and depict voices.

What is it about stories that make them such powerful vehicles? Stories can be transmitted by various media-books, audio, pictures, and theatre. Stories can recount historical events. I believe that stories can forge the path towards a greater understanding of others and self. I believe stories can teach. I believe that stories can help you learn. More importantly, "we are epistemologically and ontologically engaged in using stories as an integral way to sort out who we are as people in relation to other people" (Hasebe-Ludt, Chambers, \& Leggo, 2009, p. 152).

Clark and Rossiter (2008) state that narrative learning provides a new way to think about how learning can occur. However, how can stories actually help you learn? When we embark upon graduate studies, each one of us has a story unique to our own lived experiences. When we are in the midst of our graduate work, many of us have to conduct research. Some of us need to learn how to conduct research. We have to learn how to become researchers. However, does anyone question his/her researcher identity? Who am I as a researcher? This was a question that I found difficult to answer, as I seemed to have lost my personal identity as an individual. While I had concrete values, strong opinions, and belief systems, various personal and professional events occurred where I felt I had lost my voice. I used to speak freely. I used to speak my mind. Therefore, I am not exactly certain at what point I lost my voice. I do not think that it was one monumental event. Perhaps it was a cumulative effect of different circumstances. 
Was it because I felt I had chosen the wrong academic path and ventured into fields where I had to reeducate myself? Was it when those in leadership positions positively guided me towards unknown territories because they saw something in me and, as such, I felt that I had to prove myself to others in order to illustrate my competencies? Was it because of previous, unhealthy personal relationships where my opinion was not valued? Or was it because as children and young adults, my siblings and I were always told to remain in the background and not "stand out?" Perhaps all of these circumstances caused my voice to be suppressed and ultimately lost. It was therefore remarkable that while a qualitative research methods course at McGill University introduced me to new modes of thinking, in doing so, it also allowed me to tell my story and set the groundwork for this self-discovery and rediscovery of voice.

In embarking on this course, it became increasingly evident to me that qualitative inquiry is not simply a method to conduct analysis as a substitute for quantitative work (as had been "mildly" suggested by my scientific and engineering friends). Rather, qualitative inquiry is a rich, explorative, inquiry process that, at its core, places emphasis on voice-lost voices, subdued voices, and strong voices. Butler-Kisber (2010) describes inquiry as a holistic process and not simply as an approach or a method. She maintains that qualitative inquiry questions, "focus on what, how and why, using participant voices and experiences to interpret and explain about a phenomenon or what is happening in a certain context" (p. 26).

However, in order to effectively portray the voices of others, I believe a researcher must understand herself and be comfortable with her own voice. She must have a sense of who she is as an individual and in what form she can express this sense of self. This self-understanding and identity will help her understand who she is as a researcher, in order to effectively answer the question: "What is her researcher identity?" This, in fact, was a question asked in an early stage of my qualitative research methods course at McGill University. During this early stage, I did not believe I could lay claim to being a researcher, nor did I deem myself worthy enough to align myself with researchers whose work I admire. I thought of myself as a sponge (I soak in the experiences of others), a gatherer (I accumulate the voices of others) and an explorer (to explore the meaning of these experiences), but were these the qualities of a researcher? Most overwhelming to me was how do I accurately portray that I will one day be a capable researcher who can give a voice to my participants, when I feel that I have lost my voice.

\section{The Journey-The Pieces of the Puzzle}

While I participated in the qualitative research methods course, I discovered the power of story-telling as a means to not only learn key classroom concepts, but also as a medium to ask, explore, and learn the lessons important to the fundamental question: "Who am I as a researcher?" I created a researcher portfolio as the required class project to illustrate what I had learned about qualitative inquiry. However, this project became a personal journey towards the discovery of who I am as a researcher and who I can become as a future researcher. This portfolio described my journey of rediscovery in order for me to write this story. The portfolio explored the themes learned as part of this qualitative research methods course and utilized various elements and activities to document my story and my journey. Items included in this 
portfolio were the reflective memos from classroom activities (which included the professor's comments), my own glossary of terms, my original identity memo, and "what am I grateful for" personal cards that represented this journey. Finally, I used an epistolary approach of writing letters to myself to reflect on each stage of this journey. This, surprisingly, became an extremely personal and thought-provoking exercise, but one that I believe truly captured my understanding of the qualitative process and allowed me to explore myself. These letters made references to the class readings, exercises, and memos we had done in class, with the original intention to reflect what I had learned about qualitative inquiry and to express the emotional journey, discovery, and rediscovery of my voice. While the original intent was to simply display and relearn the exercises used in class to represent my understanding of class concepts, I soon discovered that this course allowed to me tell a story. This is my journey. This is my story about how I started to rediscover my voice.

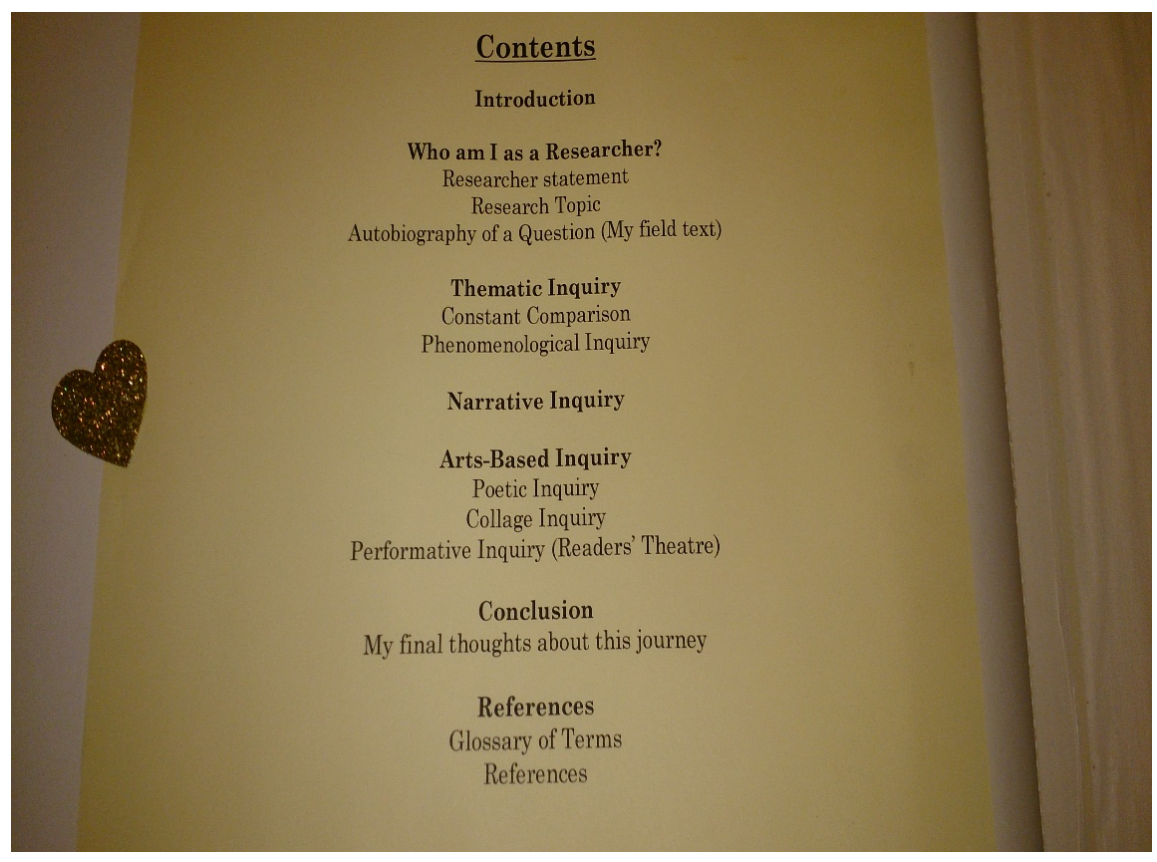

Fig 1: Table of contents: Research portfolio: "My journey of self-discovery through a qualitative lens: A rediscovery of voice."

\section{Key Elements to This Story}

Chase (2011), writes that narrative theorists define narratives as "meaning making through the shaping or ordering of experience, a way of understanding one's own or others' actions, of organizing events and objects into a meaningful whole, of connecting and seeing the consequences of actions and events over time" (p. 421). Indeed, this is how my story was constructed and how it unfolded. My story was constructed, quite simply, with a beginning, a middle, and a finale. It started with the beginning, where I asked the fundamental question of, "Who am I as a researcher"? The middle represented revisiting the various modes of inquiry learned in class and the finale described my final thoughts and conclusion about this story towards the journey of self-discovery. Additionally, for me, part of telling a story and reading a story 
involves a "lesson learned." In my story, the lessons learned were illustrated by the epistolary approach (letters to myself) and "grateful cards," which were reflections and appreciations of what I had learned.

Upon reflection, the approach I chose is a form of narrative inquiry which Chase (2011) refers to as "storytelling as lived experience" (p. 422). I told this story through my lived experiences, because the story comes afterwards [life] (Cavarero, 2000, p. 3). While this is often used for those that are oppressed, Chase states that this type of narrative is interested in how people narrate their experiences and that narration is the "practice of constructing meaningful selves, identities and realities" (p. 422). Key to this storytelling and this journey was the epistolary approach to reflect on each stage of this journey as it allowed me to reconstruct my voice and find my identity within the reality of a PhD journey.

\section{My Story}

\section{Chapter 1: The Beginning}

The beginning started with a letter to myself regarding my decision to embark upon the PhD journey. I had to ask myself difficult questions.

So, you have finally made the decision to pursue a PhD. You have finally made the decision to embark upon this journey. What took you so long? Was it because you still heard the words of your ex from so many years ago, who said that you could never succeed in $\mathrm{PhD}$ research? Was it because you wanted a break from the academic world? Was it because you, yourself, did not really believe in yourself?

Every story needs a protagonist and for this story, the protagonist is me as the researcher. The overarching question of my PhD research is whether or not "nonacademic mentors" contribute to the human performance improvement of third-year medical students. I work in an environment where I teach and interact with these students. My decision (and regret) to not pursue medical school was perhaps the reason why I wanted to help these students with whom I felt a kinship. However, when asked the question "Who am I as a researcher?", feelings of self-doubt and insecurities about my ability to become a researcher arose and I subsequently formulated the answer to this question in the form of an in-class researcher statement. This researcher statement required that I look deeply within myself to address my insecurities, my perceived limitations, and more importantly, my capacity to be the voice of, and represent, my future research participants (medical students). I revisited my proposed research topic to address these concerns and to further look within myself. 


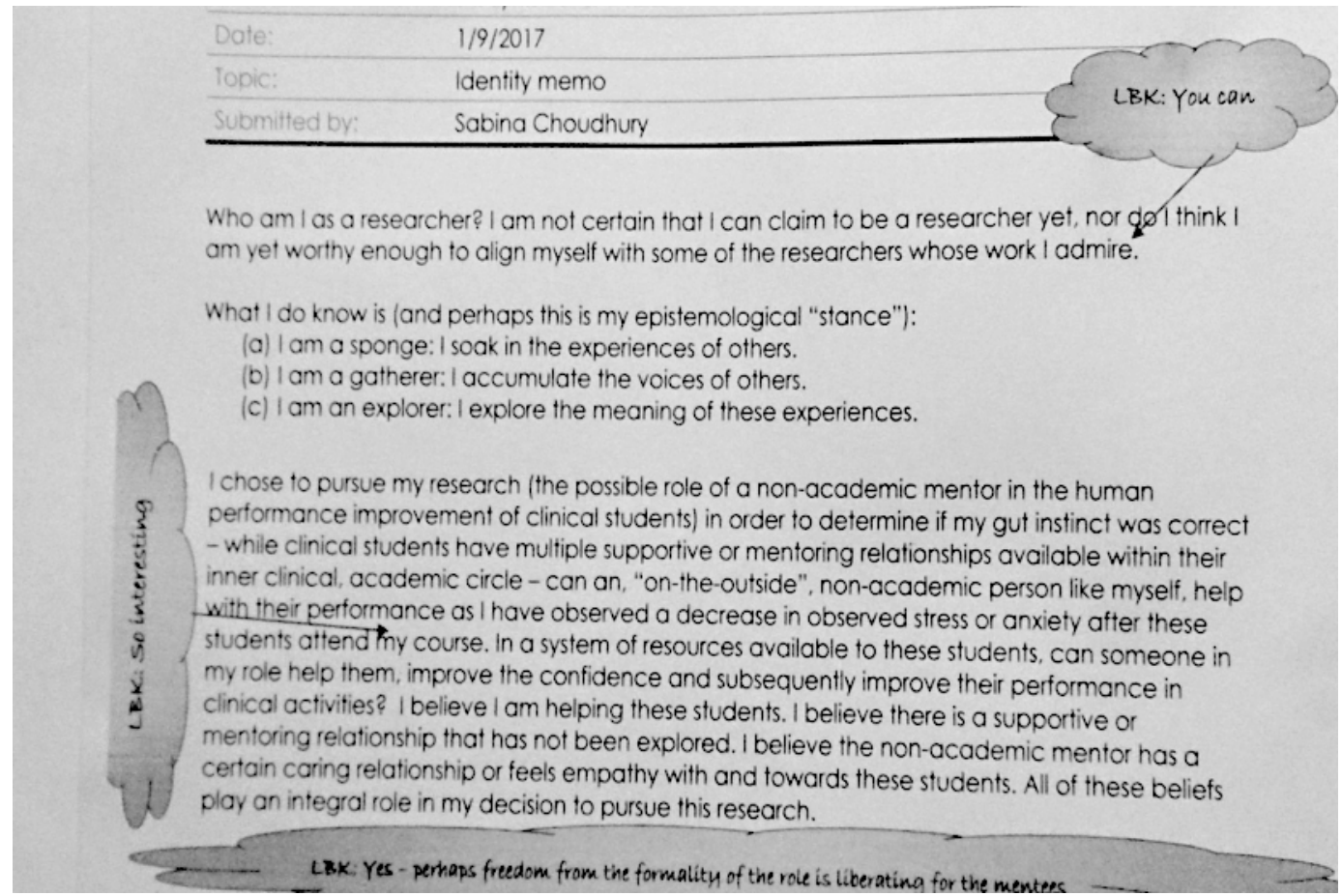

Fig 2: Identity memo. Who am I as a researcher?

A story needs a plot and the plot needs to be developed with other characters and through the relationships with these characters. In this story, the other characters are the future research participants (medical students). While the researcher statement required that I look deeply within myself (alone), it was the Autobiography of a Question (the reason for my research question) that allowed me to start to understand the relationship of who I was vis-à-vis my future research participants (medical students). These were high-achieving students, some of whom had insecurities about their chosen profession. In writing the autobiography of a question, I realized that their insecurities were not foreign to me. Looking back, I understood what these students were feeling and could relate to their pressures and anxieties. I grew up in a family with extremely high academic standards. The pressure to succeed was enormous. Thus, I felt a kinship with these high-achieving students. Digging deeper into myself, I realized that this kinship was a result of my belief that medicine was a field that I should have pursued more vigorously and perhaps my own insecurities had prevented me from this pursuit. Therefore, their voices did appeal to me. Earlier in this article, I outlined the life events where I felt that I had lost my own voice. Perhaps I was hoping to rediscover my voice with this research. To illustrate my understanding of the students' plight, I ended the autobiography with a poem that I wrote:

I am that voice

From so many years ago,

The road so clear and so bright,

But with nowhere to go 
I hear your voice

With words you might not want to say,

Like the nights in the forest

You feel you have lost your way

Can I be one of your voices,

That can help you climb to those heights

Towards your path of great promise

Together, can we make the journey all right!

In this section, I wrote a letter to myself. Here I reflected that this autobiography of a question exercise led me to a more profound and clearer understanding of the root of this research topic, given how I could relate to the insecurities of these medical students. This was the "lesson learned." I realized this lesson was an opportunity. I told myself to "use this to invigorate your research. Use this to help these students." I told myself to use my Autobiography of a Question as a field text to illustrate my process and knowledge of qualitative inquiry and to put into practice the concepts and exercises of interpretive inquiry performed in class. Through this, I was able to not only develop a better understanding of concepts learned in class, but also document my journey and my story. I was grateful for the opportunity to potentially represent the voices of my research participants and, more importantly, hope that this voice would bring some comfort to myself and those who would eventually entrust me with their stories. Unbeknownst to me at the start of this journey, this would lead me to a greater understanding of my potential as a researcher and a rediscovery of my voice. Revisiting these forms of inquiry for a class project would not only provide the possibility to give a voice to the participants, but also allow me to find my own voice.

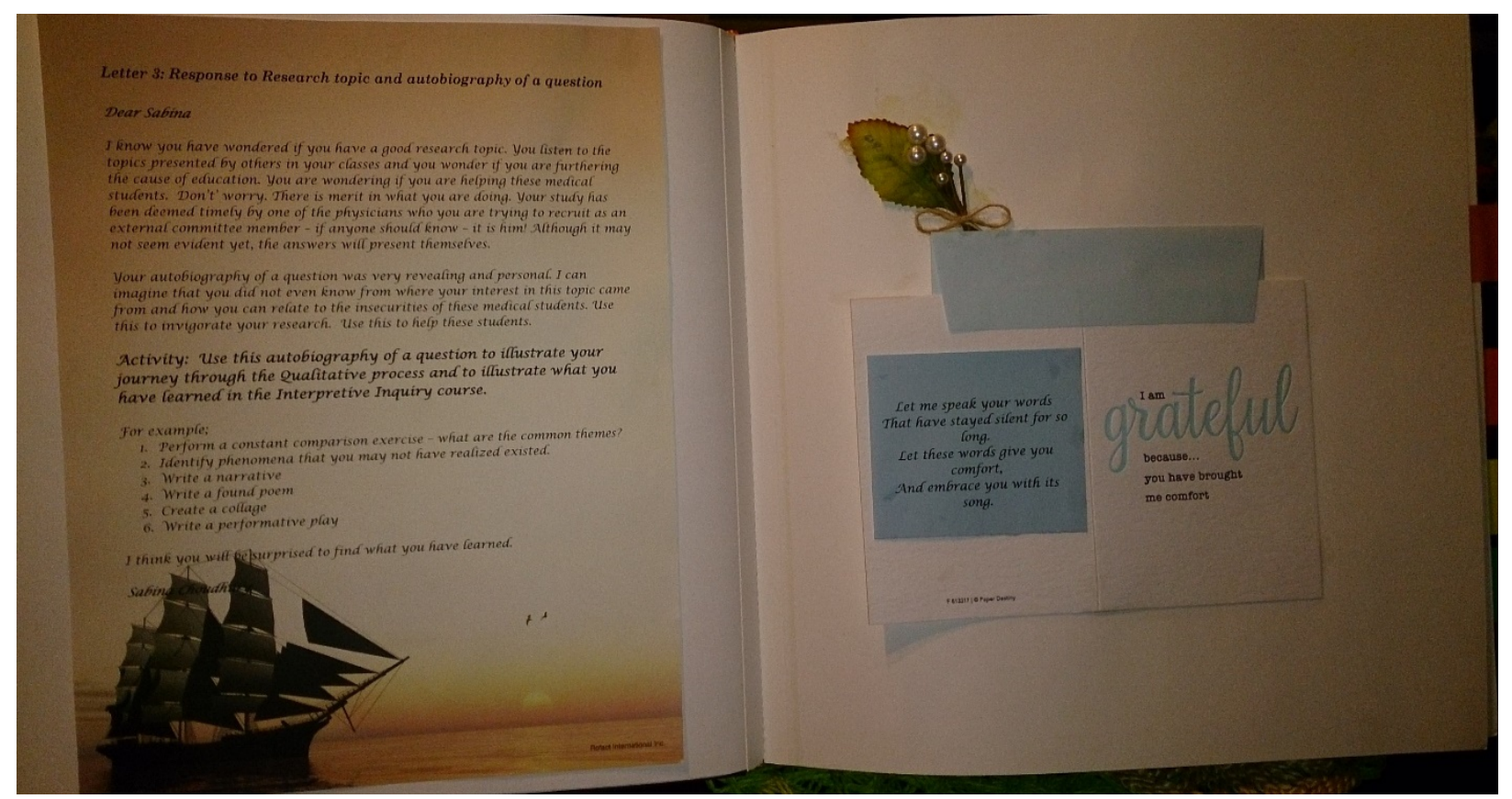

Fig 3: Letter to Sabina: Response to research topic and autobiography of a question and example of grateful card. 


\section{Chapter 2: The Middle}

The true discovery of my voice began during this middle section of the story. It was in this section where I started to explore the various modes of inquiry learned in class. Using Butler-Kisber's (2010) classification of qualitative modes of inquiry (thematic, narrative, and arts-based), I used my Autobiography of a Question written in the PhD Pro-seminar course as a field text to practice these modes of qualitative thinking. For this story, I can now say that I equated this to the life cycle of a plant: thematic inquiry was the seed, narrative inquiry was the plant, and arts-based inquiry was the flower. This activity of revisiting these modes of inquiry by using my autobiography of a question proved pivotal. In addition to being a field text, the constant rereading and analyses of this question required that I look deep within myself. This process was a journey, and this story provided the starting point for me to reclaim my voice, with the hope that, one day, I would be able to understand and portray the voices of those participants in my future research.

\section{Thematic Inquiry: The Seed}

The middle section of this story starts with Thematic Inquiry. Two forms of thematic inquiry are used to tell this story: constant comparison and phenomenological inquiry.

When I first read about constant comparison, I thought my scientific and logical approach to problem solving would render this activity easy for me. Butler-Kisber (2010) summarizes a constant comparison approach where data is organized, materials are unitized and assigned descriptive labels and codes, after which, rules of inclusion are written to define categories that can be subsequently expanded and/or collapsed. This is done in order to "reveal deeper understandings and connections" (p. 24). Maykut and Morehouse (1994) calls this the "inductive" approach to data analysis, where the data collected relate to a specific focus of inquiry, hypotheses are not generated, and variables for data collection are not predetermined. While the professor used a creative approach to illustrate this method, I found this exercise challenging. I rationalized that part of the reason was because the field text used in class was not from my own research. However, when using my own autobiography of a question as a field text for my portfolio, while a little bit easier, I again, still found this exercise and the notion of rules of inclusion quite challenging.

Phenomenological inquiry proved to be somewhat easier, albeit still challenging. In this method of inquiry, researchers must "state their intentions and biases up front, and 'bracket' these as they strive to understand the essence of the lived experience of others" (Butler-Kisber, 2010, p. 50). Initially, I found it difficult to believe that one exhaustive description could encapsulate the voices of, what I believed, are divergent views of existing phenomena.

While the first approach seemed to break down texts into smaller components in order to find different rules of inclusion, the second approach seemed to want to arrive at one exhaustive description. The fact that I found the approaches difficult seemed to be at odds with my logical, decisive approach to my work and problem solving, since both methods involve breaking down information to find themes. 
It then occurred to me, that this was the lesson learned. These somewhat contradictory approaches were almost like a metaphor to my life and my story.

Life is complicated. The rediscovery of my voice is a complicated process. Moreover, while I may want to be logical in the approaches, the path to rediscovery may be contradictory until the true voice is found. While breaking down the story of my life, into themes, the rules of inclusion can help give my voice some power to express the overall meaning. This was the initial seed that was planted in order for my voice to come through. I am grateful for these challenges as this will help me grow, further strengthen my resolve, and, ultimately, help me rediscover my voice.

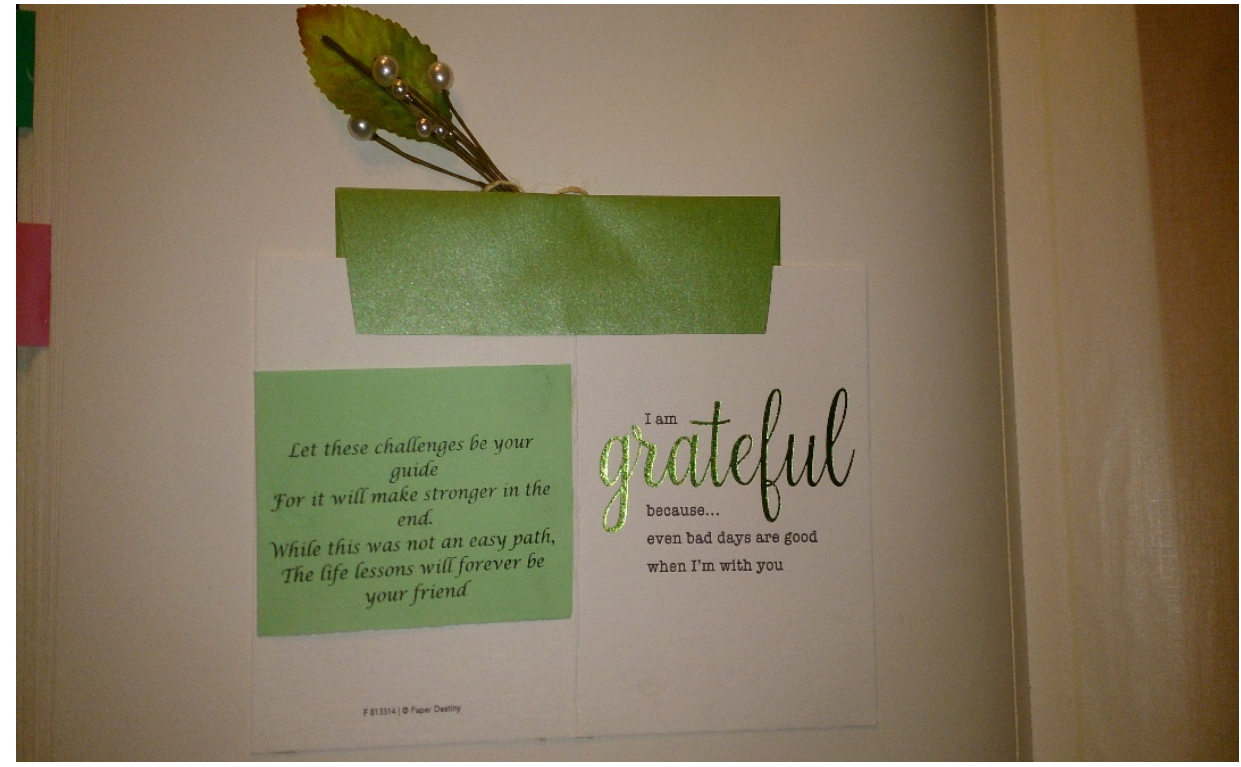

Fig 4: Grateful card in response to challenges of thematic inquiry.

\section{Narrative Inquiry: The Plant}

The narrative research process involves a strong collaboration between researcher and research subject (Moen, 2006). A narrative inquiry approach will take the life experiences of research partners as told by those who lived them (Chase, 2011). Based upon this, I was looking forward to this exercise, since I have always liked to write. However, it was still very revealing to me how narrative can be used in research and, more importantly, as a means to portray the voices of research participants.

Additionally, I was drawn to Moen's (2006) reference regarding the strong collaboration between researchers and research participants. My autobiography of a question, and the resultant letter to myself, revealed that my interest in this topic may be as a result of a perceived need to help these research participants, because of a strong affinity with them. I know about their insecurities, their anxieties, and the need to achieve excellence. I am them. This is the strong collaboration. I like the narrative approach of perhaps being the champion for this group and to represent their voices. 
Chase (2011) refers to storytelling as lived experiences and that this type of narrative is interested in how people narrate their experiences and that narration is the "practice of constructing meaningful selves, identities and realities" (p. 422). In undertaking this exercise with my own field text, my story reflected my "meaningful self." This was the lesson learned in this part of the story. I understand the plight and insecurities of these research participants. I heard their voices which resonated with my past desired identity (i.e., at a particular stage in my life, when I wished for an identity as a medical student). In understanding the participants' anxieties, I am empathizing with their struggles and giving a voice to this group. In doing so, I am also starting to reclaim my voice. This activity, therefore, led me to a deeper understanding of myself, and formed the next step towards the rediscovery of my voice. The plant was starting to grow. My voice was waiting to be heard. I am grateful to be given this opportunity to help and be heard.

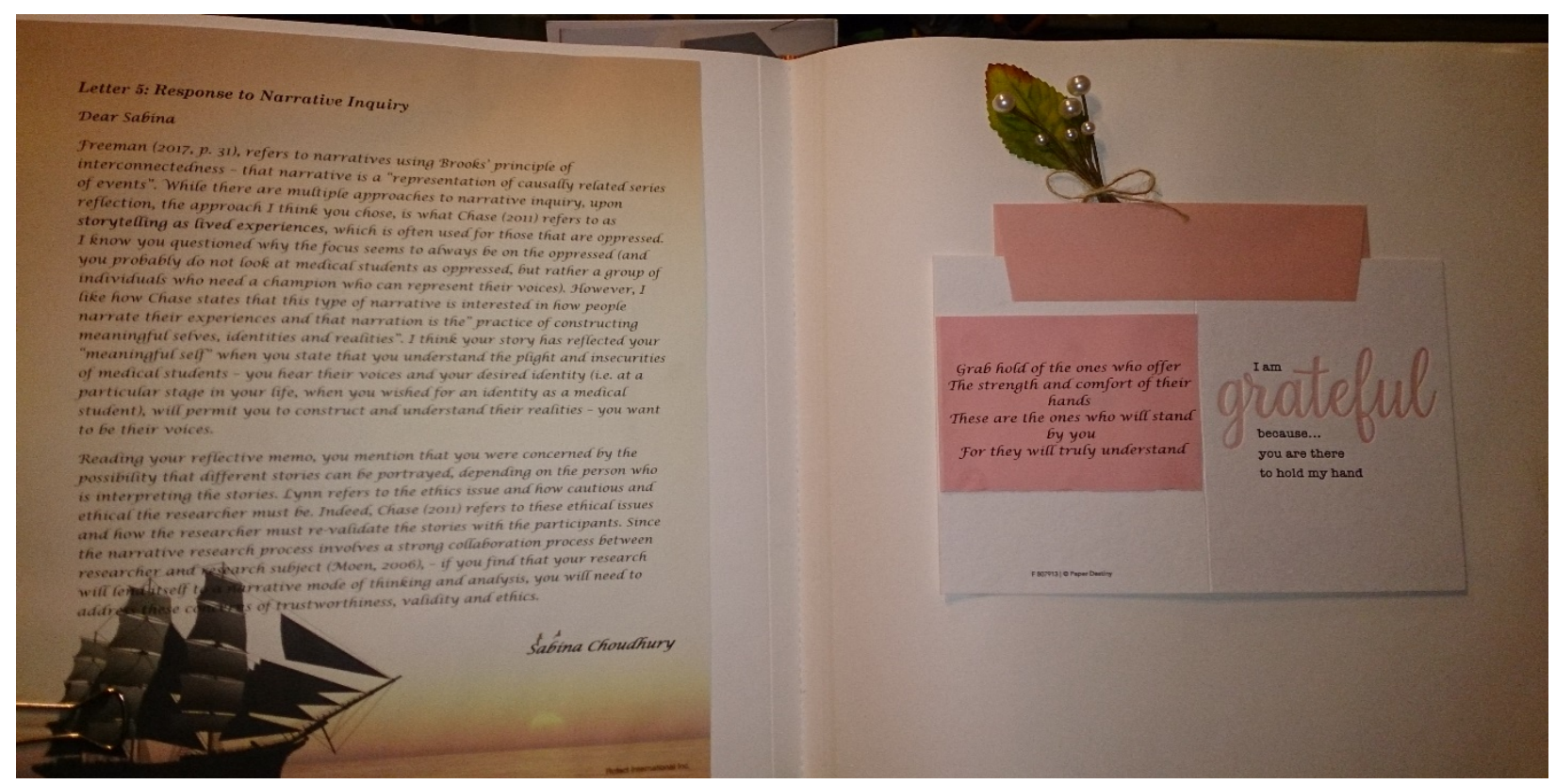

Fig 5: Letter to Sabina: Response to narrative inquiry and example of grateful card at the end of narrative inquiry.

\section{Arts-Based Inquiry: The Flower}

The three forms of arts-based inquiry explored during this journey was poetic, collage and performative inquiry (readers' theatre). These forms of inquiry were truly foreign to me, especially poetic inquiry. I was curious to explore as it would allow me to examine creative elements of myself that had laid dormant for many years.

Poetic inquiry. Freeman (2017) suggests poetical thinking, "invites, even requires participation, dwelling, a desire to be transformed, an activist engagement with the polyphony of the senses" (p. 80) and that it requires a sharing of the experience. Using the story created during the narrative exploration of this course, I created found poetry that I entitled, "Voices." Butler-Kisber (2002) defines found poetry as an approach where the researcher uses the words of the participants to create a poetic rendition of the story or phenomenon. Since I enjoy writing poetry, I was skeptical of found poetry, as I thought using other 
people's voices to represent what I want to say would diminish my own voice and feelings about a situation. However, what I found and the lesson I learned were quite the opposite during this journey of self-discovery. Found poetry is a powerful representation of participant voices, in that one has to clearly construct the phrases and verses in particular sequences so that they evoke meaning and allow readers into the participant's world. Constructing this poem allowed me to refine my own voice as I heard my own voice echoing back to me. While I was representing other voices, I found that I was also writing about my own voice. The flower was beginning to blossom.

\section{POETIC INQUIRY}

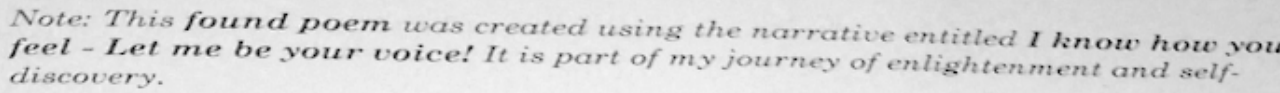

Voices

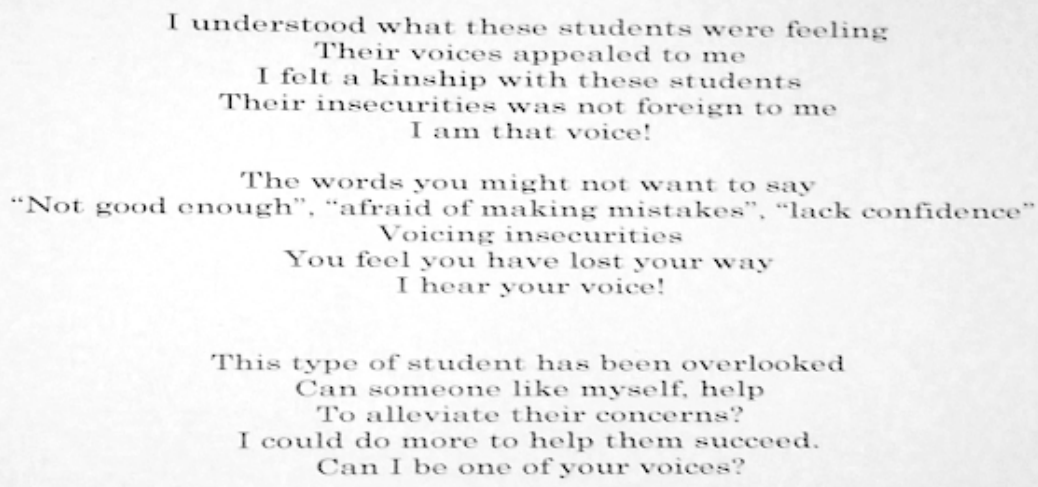

Fig 6: Found poetry: Voices.

Collage inquiry. Collage refers to an art-form which involves the "cutting and sticking found materials onto a flat surface" (Butler-Kisber, 2010, p. 102). In collage, Butler-Kisber states that the creator seeks the fragments "and glues them together to express a feeling or sense of an experience or phenomenon rather than a particular idea" (p. 104). I attempted to use a partial Markus approach where the researcher picks a focus, creates the collage, picks a title, and then writes a paragraph describing what the collage is about (p. 105). This method was used in an effort to represent the feelings that led to my research question and the feelings elicited by the autobiography of a question. Initially uncomfortable with collage (as I do not consider myself visual), I decided to incorporate Gerstenblatt's (2004) description of image that allows for the inclusion of words, since I was more comfortable with words. Entitled "Life's Common Core - Shared Legacy," I was able to let creative juices flow and express what I thought was the shared legacy between myself as the researcher and research participants. This inquiry, I thought, was the turning point in this rediscovery of voice. I was quite afraid that my perceived inability to do collage work would render my work as inadequate to 
myself, my classmates, and my professor. What I did learn was, "even if you are afraid, do it anyway!" The flower was beginning to grow its petals. My voice was becoming stronger.

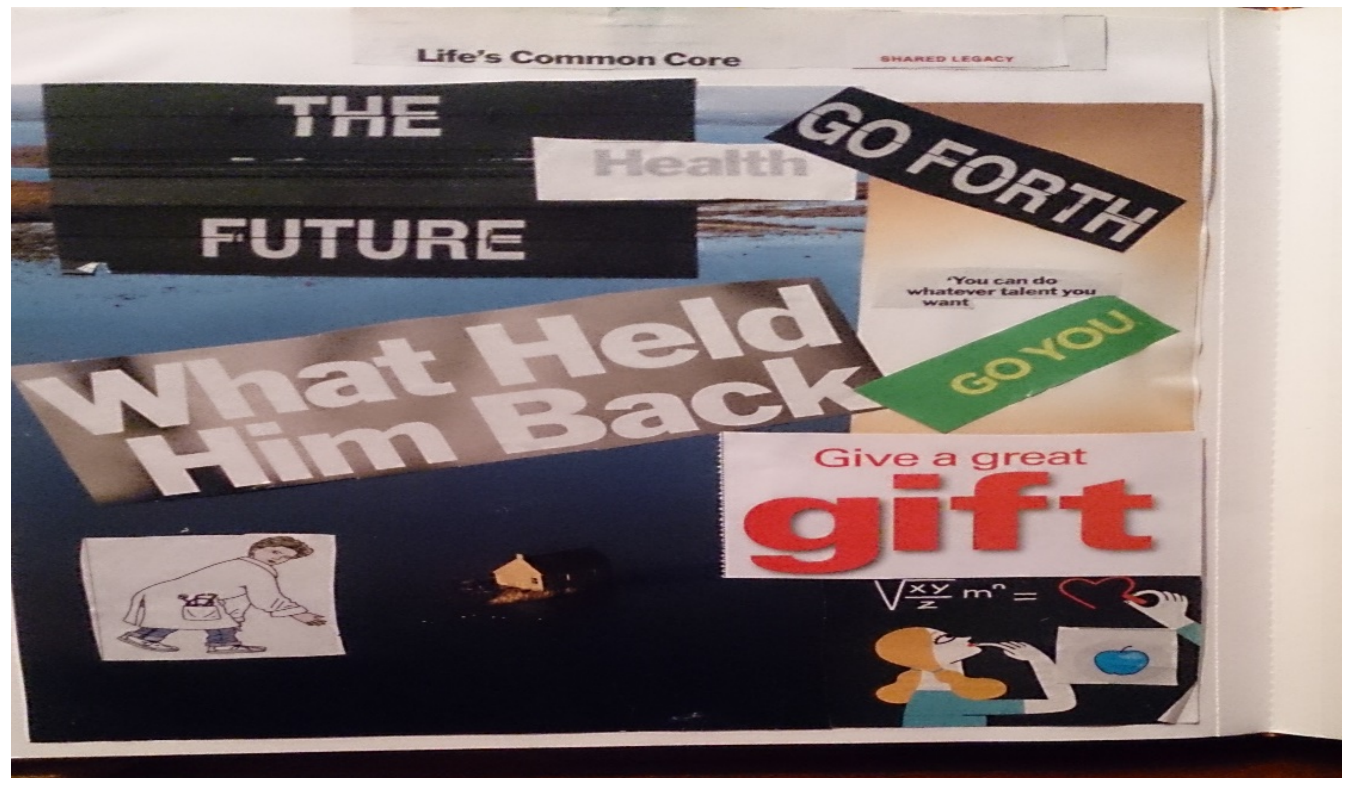

Fig 7: Collage creation: Life's common core - Shared legacy.

\section{Performative / Readers' Theatre}

I will be completely honest. When I read articles on performative inquiry and readers' theatre, I was skeptical and questioned whether "you can perform your data." I quickly changed my mind when I wrote the readers' theatre for the class exercise and for this portfolio. Readers' theatre is a "joint dramatic reading from a text, usually with no memorization, no movement and a minimum of props" (Butler-Kisber, 2010, p. 140). What makes the arts and literary techniques work well in education is that education is an "applied" field (Donmoyer \& Donmoyer, 2008). What I learned was how revealing and intimate this process is - it is "getting to the bare soul" of the participants' voices. I think they are correct. By writing and performing readers' theatre, you are, in essence, participating in all roles. It is as if you are required to know and feel these different perspectives. Donmoyer and Donmoyer (2008) further elaborated: "For Brecht, in other words, theatre should never be escapist or tie things up in neat and tidy packages" (p. 213). Rather, it should encourage thought as well as emotion and provoke analysis. In this story, writing for and performing the various roles of the future research participants (medical students), invariably required some form of analysis of what I think their emotions would be, in order to accurately portray a meaningful performance.

Whatever voice I had lost can be best summarized, expressed, explored, and reclaimed by Brecht's simple statement (see Fig. 8). What I discovered was that my voice can represent whatever is in my thoughts. My voice is laden with emotion. My voice can provoke analysis, from myself or from others. I have a voice and my voice needs to be heard. I am starting to know my voice. Now that I have my voice, I can start to be the voice of others. I am not certain how, yet, or how I can use my 
voice to resonate with or speak for others, but this is a step in the right direction. I have found my voice. The flower was in full bloom.

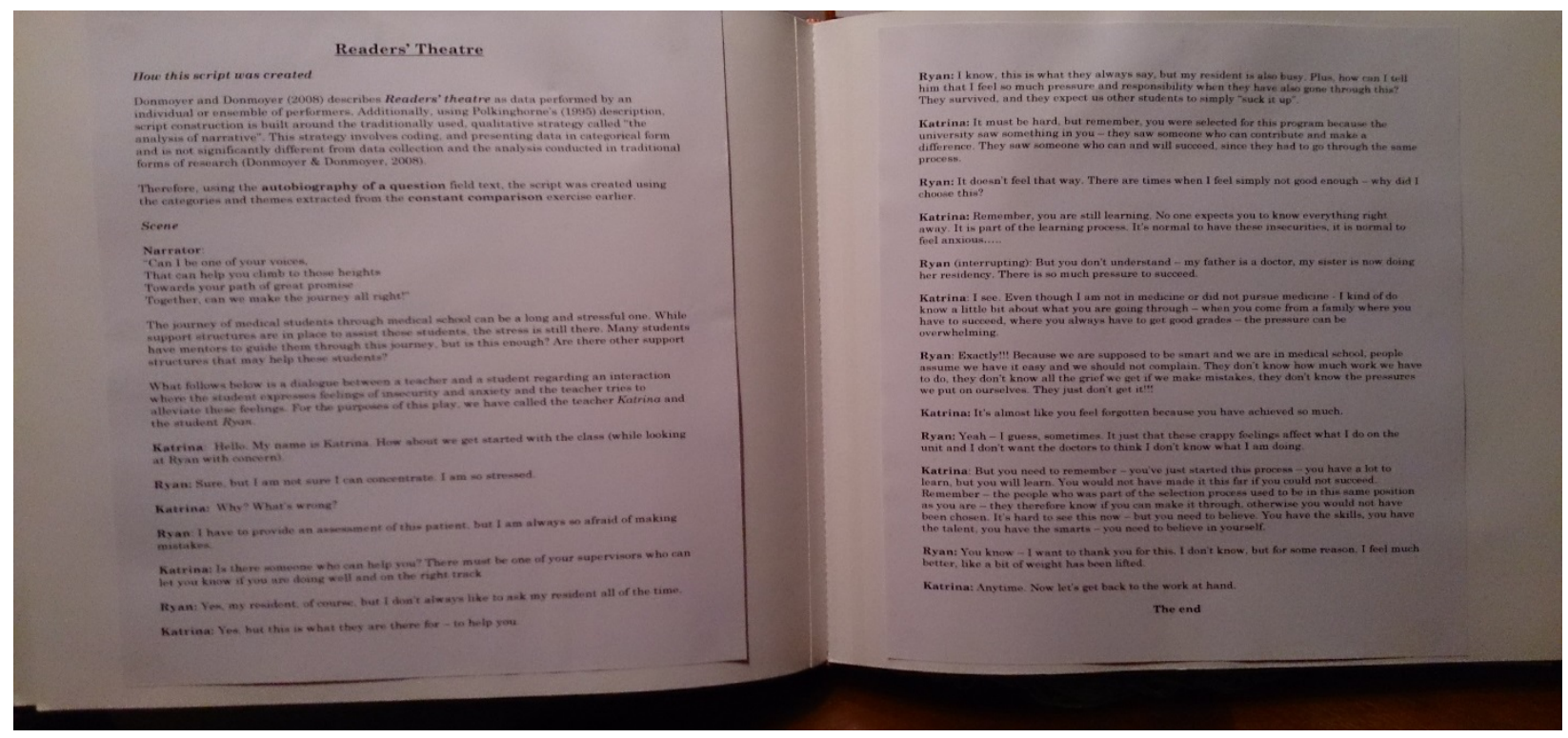

Fig 8: Readers' Theatre - I know how you feel (Brecht, 1992).

I was grateful for this opportunity to go beyond my comfort zone and to not be afraid to explore these unknown concepts. What better way to rediscover voice than to jump into unchartered waters. I started from a place of relative safety and familiarity (poetry), where my voice could speak with relative ease. During the collage activity, I dipped my toe in cold water to test the temperature. What I found was that my voice was permitted to come out, with no judgment from others. I reached the peak of the mountain with readers' theatre. Writing and reading from the perspective of others allowed me to start to explore and understand their voices. In doing so, my own voice became stronger. I was rediscovering the power of my voice.

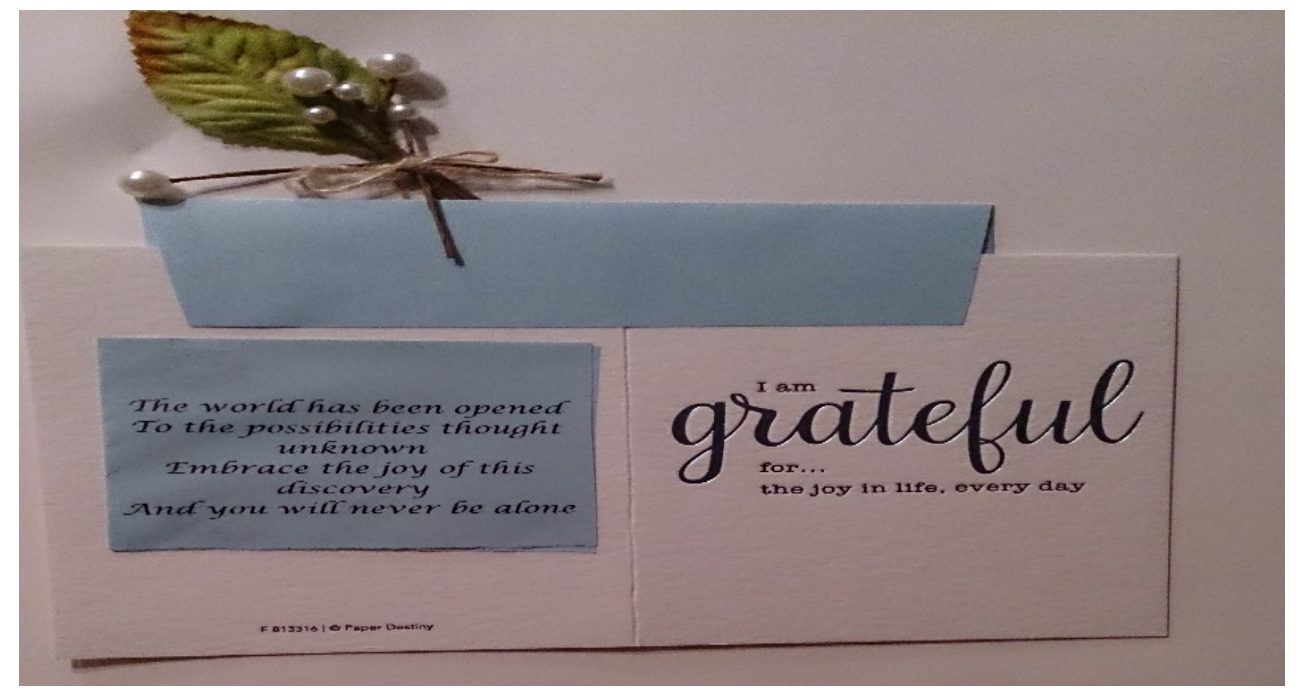

Fig 9: Grateful card in response to what had been discovered using arts-based inquiry. 


\section{Chapter 3: The Finale}

This activity started off as a class requirement to create a research portfolio. It became a story about self-discovery through a qualitative lens whereby I rediscovered my voice. In creating this narrative and constructing my story, the pieces of my researcher self were coming together-this narrative helped me learn and I was beginning to make sense of my researcher identity (Clark \& Rossiter, 2008). This story used elements and activities from classroom sessions (reflective memos, glossary of terms, etc.), reexplored the various modes of qualitative inquiry (thematic, narrative, and arts-based), and ended with an epistolary approach of letters to myself which served as reflective memos of this journey. As mentioned earlier, I felt that these letters developed into an intimate portrait of myself, where I was forced to look deep within myself, to understand my limitations, to self-reflect on the process and my understanding of these concepts. This opened the doors towards the analysis required to rediscover my voice. This became my story.

Why is this story important? More importantly, is this story important? In his 1995 article, "Memory comes before knowledge - Research may improve if researchers remember their motives," Hampton asks, "What do I have as a human being to contribute to this topic?" (p. 47) As human beings, Hampton references a teacher who said, "humans only have three things - time, space and energy" (p. 47). Feeling that this description was limited, Hampton added spirit and emotion; "the feelings of being alive and the emotions that we feel every day" (p. 47). He says that research is about learning. While some people may think that research is about creating knowledge, Hampton believes that he is not arrogant to assume this. I, like Hampton, also do not think I am this arrogant. I subscribe to Hampton's view that the "motive behind research is emotional because we feel" (p. 52). I need to learn about and understand who I am as a researcher in order to conduct research. This involves getting to the crux of the emotional me. Just like Hampton, I also "appreciate the opportunity to talk today about things that are important to me" (p. 54). What we do "for reasons and those reasons are connected to how we feel" (p. 54) and care. "We do things for reasons and those reasons are connected to how we feel" (p. 54).

In the beginning, I felt I had no voice. I had lost my voice. This was a story with no words. A story with no protagonist. A story with no plot. I was expected to become a researcher, but with no voice. How can I possibly give a voice to my participants if I myself had no voice?

For me, teaching and learning modes of qualitative thinking were an excellent illustration of how stories can be told and how voices can be discovered and rediscovered. Through the power of written field texts, exploration of themes, development of narrative, and creation of various art-based media (poetry, collage, readers' theatre), the stories that one can tell and the voices that can be unleashed are incredible. This seed was planted when exploring thematic inquiry. Having an appreciation for this structured approach resonated with my orderly way of working, but this was not enough for my voice to come out. The seed started to develop into a plant with the narrative mode of thinking. My voice started to grow in telling my story of the students for whom I think I can help. It was not until the plant grew flowers (arts-based inquiry) that my voice started to roar. These modes of thinking were completely new to me (from a research perspective), but in practicing them I was given a forum to explore and try without fear 
of criticism or reprisals. This act of exploration without fear allowed me to rediscover my voice. Is this permanent? Only time will tell. Will the PhD journey and life events erode this self-confidence and therefore diminish my voice? Perhaps. However, what I do know is that no matter what events come my way, the true voice does not and will not be muted.

So how does this story end? Is there an ending? I equated the exploration into qualitative modes of thinking to the life cycle of a plant, but some plants and their flowers eventually die. However, the plant leaves seeds that will create other plants. The same can be said of voices. If we document our own voices and the voices of others and continue to tell stories, these voices never die. The voices may become soft, they may become low, they may become temporarily silenced, but once the voices start to speak and the story is told, the story and the voice lives forever.

Therefore, what is my researcher identity? It is still a work in progress, but what I do know is that creating this research portfolio provided the starting point for me to reclaim my voice, with the hope that, one day, I would be able to understand and portray the voices of those participants in my future research. This is the identity I want to establish as a researcher.

Is there a moral to this story? I am not sure. However, what I do know is that the journey documented through these reflective letters and this process, became almost a metaphor for my life. I learned that at each stage, you need to stop, pause, think, reflect, and always remain grateful. I am truly grateful for the opportunities this qualitative research methods course has offered me and for the opportunity to explore different modes of analysis and thinking. I am also grateful that this course and portfolio have allowed me to slowly rediscover my voice and have given me the freedom to learn, explore, fall, and get back up to try again. To me, this was how I started to find my voice. This process was a journey, providing the starting point for me to reclaim my voice, with the hope that, one day, I would be able to understand and portray the voices of those participants in my future research. This is my story. This is my voice. Now that it is written, this story and my voice, will live forever. I can now start the next story-the story of my research participants.

\section{References}

Brecht, B. (1992). Brecht on theatre: The development of an aesthetic (J. Willet, Trans.). New York, NY: Hill and Wing.

Butler-Kisber, L. (2002). Artful portrayals in qualitative inquiry: The road to found poetry and beyond. The Alberta Journal of Educational Research, XLVIII (3), 229-239.

Butler-Kisber, L. (2010). Qualitative inquiry: Thematic, narrative and arts-informed perspectives. London: Sage Publications Ltd.

Cavarero, A. (2000). Relating narratives: Storytelling and selfhood. London: Routledge.

Chase, S.E. (2011). Narrative inquiry: Still a field in the making. In N.K. Denzin \& Y.S Lincoln (Eds.), The Sage handbook of qualitative research, 4th edition (pp. 421-434), Thousand Oaks, CA: Sage. 
Clark, M., \& Rossiter, M. (2008). Narrative learning in adulthood. New Directions for Adult and Continuing Education, 119, 61-70.

Donmoyer, R., \& Donmoyer, J.Y. (2008). Readers' theater as a data display strategy. In G. Knowles and A. Coles (Eds.), Handbook of the arts in qualitative research. Perspectives, methodologies, examples and issues (pp. 209-224). Thousand Oaks, CA: Sage.

Freeman, M. (2017). Modes of thinking for qualitative data analysis. New York, NY: Routledge.

Gerstenblatt, P. (2004). Collage portraits as a method of analysis. International Journal of Qualitative Methods, 12, 294-309.

Hampton, E. (1995). Memory comes before knowledge: Research may improve if researchers remember their motives. Canadian Journal of Native Education, 21, 46-54.

Hasebe-Ludt, E., Chambers, C., \& Leggo, C. (2009). Life writing and literary métissage as an ethos for our times. New York, NY: Peter Lang.

Lahiri. J. (2014). The lowland. Canada: Vintage Canada.

Maykut, P., \& Morehouse, R. (1994). Beginning qualitative research: A philosophic and practical guide. New York, NY: Falmer Press.

Moen, T. (2006). Reflections on the narrative research approach. International Journal of Qualitative Methods, 5(4), 1-11.

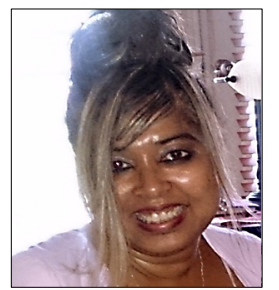

Sabina Choudhury works in the Information Technology department of the McGill University Health Centre (MUHC) and is involved in the professional development of clinical staff regarding the use of the Electronic Medical Record (EMR). She is also a PhD student at the Department of Integrated Studies in Education at McGill University. Her current research interest focuses on the role of mentoring in the human performance improvement of clinical students. 
92 | LEARNing Landscapes | Spring 2018, Vol. 11 No. 2 